\title{
Egyptology and Global History: An Introduction
}

The publication of this special issue of the Journal of Egyptian History intends to explore the place and role of Egyptology in Global History, as well as its potential contributions to this burgeoning field of research. In order to achieve this goal, the journal's editors have considered it useful to invite scholars who are not Egyptologists, but whose expertise in topics and regions that are increasingly relevant for a better comprehension of ancient Egypt will certainly stimulate both interdisciplinary dialogue and a better integration of data from the land of the pharaohs into current debates in social sciences. Other articles intend to explore new paths of comparative research, for instance about concepts that helped define the political and social principles that guided the everyday exercise of political action in ancient societies, or the way in which the past was recorded and mobilized for practical reasons. Connectivity is also becoming a major focus of research in archaeology and ancient history, and it increasingly reveals the influence that particular cultural, technical, or economic phenomena exerted over major developments across vast spaces. So, the modalities of integration of ancient Egypt (a marginal actor or an unsuspected influence?) in these spheres of interaction is certain to gain momentum in the next decades. They may also help scholars to understand the nature of the relations or the type of the policies followed by Pharaohs and by other actors (traders, agents of the crown, etc.) toward neighbouring areas. In return, they may also shed light on major changes that occurred in Egypt and which share, nevertheless, common features with other regions of the ancient Near East. One final urgent question concerns the role Egyptology is called to play in a shifting cultural, educational, and intellectual landscape no longer centred on the cultural priorities and geopolitical goals of the West. The articles gathered in this special issue try to cast some light on these topics, and it is the editors' hope that they will stimulate debates among Egyptologists as well as with specialists working on neighbouring disciplines and, more generally, on social sciences.

Global History is now an increasingly important sub-discipline in historical studies. The end of the colonial empires in Africa and Asia, and the subsequent foundation of many states in these regions, was followed by a deep 
reconsideration of the historical narratives created by the West to justify its domination over these territories. Eurocentrism and Orientalism were the most visible, though not exclusive, pillars of such narratives. They were also based on the idea of irresistible progress, as if the historical path followed by the West was ineluctable and unique, the model to imitate by any state aiming to reach modernity and the economic prosperity, political maturity, and intellectual prowess associated with it. Consequently, "decentralization" of prevalent historical narratives appeared as an urgent task and sparked multinational ambitious research projects, like those inspired by UNESCO and by the nascent states in Asia and Africa. Their aim was to explore their own longneglected pasts according to solid scientific methods and to dignify their own traditions, far from the dominant univocal Eurocentric narratives that had prevailed until then. In their effort to get a more balanced knowledge of the past, these projects took the challenge of exploring — often for the first time-the history of territories about which little was known.

It was not uncommon that their precolonial pasts had been utterly ignored in the histories written by colonial powers, and their "true" history thought to begin with their discovery and colonization by a Western state. There was also some urgency in promoting new historiographic projects because the new states born in Africa and Asia kept, in general, the arbitrary borders created by the colonial powers, perhaps the most famous (or infamous) being those imposed on Africa, the Near East, and the Indian subcontinent. Grouping different peoples under a single state while splitting other peoples among diverse political entities, not to mention the problems raised by mobile populations now forced to suffer controls and restrictions when crossing national borders, today remain chronic sources of political unrest. Under these circumstances, the creation of a sense of national community, to justify the very existence of states created anew, was an urgent task that faced formidable challenges, especially when they clashed against alternative, too alive sources of social identity, based on ethnicity, mobility, or religion. It was not rare that the mere implementation of educational models, economic strategies, or intellectual concepts that originated in the West (from the very idea of "nation" to that of "socialism," from industrialization to secularism) provoked reactions that claimed in some cases for a return to idealized pre-colonial identities, considered best suited to preserve the endangered communal values and traditional lifestyles of populations anxious about their future and about their place in the new states. Neo-tribalism versus Pan-Arabism and religion versus secularity illustrate some of these tendencies, among many others. In this light, one of the reasons that explains the success of Global History as a discipline is its capacity to 
dignify the pasts of former colonial territories and to challenge the narratives that celebrated the "rise of the West" as a unique case in history.

Another reason is geopolitics. During the last decades, East Asia has become the most dynamic economic area of the world, a process concomitant with the gradual loss of political centrality, economic weight, and cultural appeal of the West. This shift to the East further challenges the historical narratives that celebrated the uniqueness of the West, its apparent success-story based on economic prosperity, democracy, and intellectual superiority (at least as measured by technological progress and scientific achievements). The consequence is a thorough rethinking of the historical path followed by East Asian states, not as mere imitators of models and processes that appeared elsewhere in the world (capitalism, industrialization), but as raising successful powers thanks to their idiosyncratic cultural and social values and their own historical trajectories, which show potential alternative ways toward modernity. What is more, Western democracy, liberal values, and free markets are no longer regarded as desirable ends in themselves, whereas social discipline, restricted freedom, and state intervention are justified as rooted in long traditions and on a certain "Asian way of life." It is not by chance that recent controversies revolving around concepts such as "civilization-states" (instead of Western nation-states) or "the great divergence" aim to revalorize the history, culture, and values of Asian powers (mostly China and India) and to promote a feeling of self-centred identity and national pride that would owe little to foreign influences.

Quite paradoxically, these moves have been preceded, and accompanied recently, by historical narratives based on concepts such as connectivity and globalization. Popular models like world-system(s) theory paved the way to this shift in perspective as they highlighted the importance of international exchanges, division of work, and regional specialization as crucial moves toward an increasing economic integration of the world. One can think, for instance, of the role of India, Persia, and South-East Asia in the emergence of the Indian Ocean as a vast trading and exchange sphere whose economic prosperity owed little to the influence of European powers until the eighteenth century. Nowadays, a second axis emerges, focused on Eurasia and Eurasian integration, with the Silk Road invoked as the main vector of Chinese influence in trading and cultural networks spreading across Central Asia, the Sub-Indian continent, the Middle East, and beyond (including coastal East Africa). A consequence of these new perspectives is the view that the roots of world-systems and globalization could be found in Classical Antiquity, as early as the Bronze Age if not before. 
In a way, these narratives contribute to fill the gap left by the end of the great narratives centred on the West and the cultural and political projects they served, from Enlightenment to progress, from liberalism to socialism. Globalization favours instead the integration of a diversity of actors, cultural values, historical paths and interactions without any clearly defined hierarchy, in which different areas of the world influence each other and in which ideas, goods, and people circulate and their achievements are recognized as precious contributions to a common, universal pool of human experience-one in which the West is merely one actor among others. However, globalization, postmodernism, and post-colonial perspectives are often accused of inspiring a cultural relativism that blurs the construction of coherent historical and large-scale narratives. Yet this impression may be misleading, because other narratives, inspired by economics, not only accept globalization and exchanges as their referential frameworks, but help in "naturalizing" some institutions and values (markets, economic rationality, law) interpreted now as central in human dynamics, yet defined according to Western values and considered neutral and universally valid.

It comes then as no surprise that comparative history and comparative research in social sciences are undergoing a recent revival and contributing to a deeper and more nuanced comprehension of basic concepts (state, city) and economic activities (division of labour, trade) in ancient studies. Archaeology has played a pivotal role in this development. On the one hand, archaeological research in areas traditionally neglected (like Africa) or whose results were not easily accessible to a Western public (like the excavations carried out in former USSR or in Maoist China), have provided a wealth of data about forms of social, territorial, and economic organization that challenge traditional models based on a rather limited number of case studies and regions of the world. Thus, for instance, the sizeable settlements discovered in the Niger floodplain or in Ukraine challenge the model of early urbanism established by Gordon Childe, and reveal the importance of heterarchical communities as well as of non-centralized forms of management of complex societies. The plethora of archaeological data from pre-Columbian Mesoamerica and Andean America also reveals the fragile nature of oligarchical forms of power capable, nevertheless, of creating magnificent architectural complexes (and thus makes one think about a rigid centralization of power under absolute rulers), in contrast with the resilience of dispersed settlements and autonomous households. In other cases, the very structure of states has benefited from the comparison between two or more ancient polities, China and Rome having been privileged in recent discussions, while at the same time comparative research with the ancient world has stimulated rethinking the foundations of early Middle Age 
European states and economies. Scholars now regularly analyse concepts such as "empire" and "state" not only in the light of comparisons between ancient societies, but also inspired by contemporary political philosophy and political sociology. In all these cases it is most regrettable that pharaonic Egypt has played a marginal role and contributed little or nothing to most of these inspiring debates.

Seen in this light, the particularities of Egyptology as a scientific field are only intelligible when considering the very particular cultural and social context in which it appeared and the cultural expectations it was supposed to fulfil in the nineteenth century. This was a time in which nation-states were reshaping and redefining European societies and identities and, in so doing, they were also replacing former feelings of communal belonging and of social hierarchy. Concomitantly, nation-states imagined themselves as the most achieved political form, the outcome of an interrupted process of continuous progress through history, of which the venerable and prestigious roots went back to the Greco-Roman world and, beyond it, to the "cradle of civilization"Egypt and Mesopotamia. Alongside this, Christianity remained still central in the definition of European identities and values during the nineteenth century, and Egypt provided unforgettable colourful stories narrated in the Bible, from Moses and Joseph to the flight of Jesus into the Nile Valley. Pharaoh too became the synonym of despotic absolute "oriental" rule, whose alleged immobility represented the perfect opposite to the dynamic Western democracies and their liberal political systems.

But if ancient Egypt and Egyptology have provided traditionally a crucial link between past and present in the construction of historical narratives that highlighted the "uniqueness of the West," one can wonder about the place reserved for Egyptology in a world where the West declines, where East Asia gains geopolitical and economic power, and where the decried "orientalism" in which ancient Egypt once played a crucial role appears now outdated and unjustifiable. To put it in other words, will Egyptology be capable of surviving in a world in which humanities are losing their former cultural importance and prestige, particularly its role as the "cultural glue" that holds national communities together? A world in which East Asia (and, more particularly, India and China) are tracing alternative paths of historical development, from antiquity to contemporary times, based on their own history and cultural values, that owe nothing to ancient Egypt or to Classical Antiquity? How could ancient Egypt be integrated in the emerging historical narratives in which connectivity and foreign exchanges will probably replace (or, at least, reduce) the importance of states as a privileged topic of historical reflection, contrary to their centrality in nineteenth century Europe and in its diverse nation-building 
experiences? Finally, what will be the place of Egyptology in shaping the identity of contemporary Egypt? As for the narratives created by Western powers to address their own cultural needs and expectations, will they continue to be accepted by a country more and more turned to the East for economic and geopolitical reasons? And, will a too self-centred discipline like Egyptology be capable of dialogue with, and to contribute productively to, social sciences, and to address crucial questions about our own societies, about the expressions that culture, research, and education will take in our changing societies?

Global History opens thus a challenging but unavoidable setting that will mark both historical thinking and the future of Egyptology in the decades to come. It will also put under pressure outdated perspectives, methods, and academic traditions that still hamper a fruitful integration of ancient Egypt in current debates in social sciences. Yet Global History also offers many opportunities to analyse Egyptian sources and research topics under a new light. What is more, the land of the pharaohs may — and can — enrich discussions on crucial topics, like urbanism, trading organization, political structure, cultural innovations, etc., opening new perspectives and stimulating comparative research. Seen in this light, challenges thus appear inseparable from opportunities, and Global History will certainly help to rethink and renew a discipline whose main topics and perspectives of historical research are still rooted in debates and conceptual frameworks dating back to the late nineteenth and early twentieth centuries.

Juan Carlos Moreno García 